\title{
The Role of Simultaneous Pursuing of Academic and Athletic Activities over Youth in Personality Development
}

\author{
Iryna Arshava ${ }^{1}$, Dina Nosenko ${ }^{1}$, Ganna Nosenko ${ }^{2}$, Anton Sayevich ${ }^{2}$ \\ ${ }^{1}$ Department of General and Medical Psychology, Dnipropetrovsk National University, Dnipropetrovsk, Ukraine \\ ${ }^{2}$ Projects Managements, Dnipropetrovsk Regional Institute of Public Administration, the National Academy of \\ Public Administration of Ukraine, Dnipropetrovsk, Ukraine \\ Email: enosenko2001@mail.ru, iarshava@mail.ru
}

Received December $30^{\text {th }}, 2012$; revised January $27^{\text {th }}, 2013$; accepted February $26^{\text {th }}, 2013$

\begin{abstract}
In search of approaches to defining the psychological life history of an individual the contemporary personality psychologists address the individual differences in behavior reflecting the interplay of the specific real life situations and the new dynamic contextualized trait constructs which can cast light on the within-person causal dynamics. The participants of the research - thirty University-level student-athletes and 109 secondary college-level students, simultaneously pursuing the academic and athletic activities, were shown to display different levels of personality self-evolution under this specific situation depending on the sporting achievements attained. Clustering the samples (K-means algorithm) into the two groups each, which significantly differed on the personality variables, indicative of the self-evolution dynamics, showed that the higher was the level of sporting achievements the more significantly the participants appeared to differ on the patterns of coping strategies preferred, the emotional intelligence abilities, hardiness and dispositional resources of self-evolution acquired. Equally high levels of internal locus of control and the mental health continuum measures in both clusters of the university-level student-athletes can also be regarded as favorable outcomes of combining two significant life activities for stimulating the personality development.
\end{abstract}

Keywords: Sporting and Academic Activities; Levels of Achievements; Personality Development

\section{Introduction}

The concept of personality development, operationalized in terms of the qualitative changes in the consciousness and behavior of the personality, which are determined by the ontogenetic and situational factors, is a key issue of the research of individual differences in the real life settings. In the mainstream personality theories those differences are ascribed to the interplay of a relatively small number of stable dispositional traits and situational factors, while contemporary personality psychologists argue that it is necessary to "push out the frontiers" in search of a realistic answer to Gordon Allport's defining question for the personality "How shall a psychological life history of an individual be written?" (Campbell, 2008).

Some promising answers to that rhetoric question have been suggested by the contributors of the latest SAGE Handbook of Personality Theory and Assessment (Boyle, Matthews, \& Saklofske, 2008), who claim that the individual specificity of behavior in the real-life settings is better explained not by the global trait features, but by the so-called explanatory models of personality (Cervone et al., 2006) by "specific adaptations" (Parker et al., 2004); new dynamic trait constructs (Austin, Saklofske, \& Egan, 2005) and the like.

The applied project described in this paper is specifically concerned with providing an illustrative example of the relevance of seeking alternative strategies for personality science by investigating personality constructs on the borderline between abilities and personality (like emotional intelligence); self-regulation and personality (like individually preferred coping strategies); values-in-action and personality (like character strengths), recently identified by positive psychologists (Peterson \& Seligman,2004). This research also illustrates the significance of tracing dispositional stability and change of the personality not across everyday life situations, but across functionality equivalent specific situations. As Cervone (2008) reasonably argued, the Big Five model, for one, addresses only between-person differences and cannot cast any light on the within-person casual dynamics, which lets itself for observation under specific functionally equivalent situations or capture the qualities of any individual person.

\section{A Framework of Investigating Personality Development in a Real-Life Specific Context}

The uniqueness of the situation of simultaneous pursuing of two equally significant activities for the personality development and self-determination, chosen in this paper to illustrate an adequate approach to studying some defining features of the personality, has not yet been, to our knowledge, analyzed in this capacity earlier, though there is a sufficient amount of research findings which demonstrate the impact of athletic and academic activities, viewed separately, on some important aspects of personality development. For example, it was reported that mental health toughness and hardiness characterized members of the Rugby League (Golby \& Sheard, 2004), determined success in basketball (Maadi \& Hess, 1992). Thanks to the moderating role of commitment in achieving the academic study success, the latter was also found out to be related to hardiness 
(Sheard, 2007). Athletic activities appeared to enhance emotional stability of the person (Chebykin \& Abolin, 1984); the high-achievers in tennis were shown to display preference to choosing problem-focused copying strategy in dealing with stressful sporting situations, while non-achievers resorted more frequently to the emotion-focused coping style (Arshava, Nosenko, \& Ponomareva, 2010).

The programs, stimulating student-athletes to go in for sports in a big way in the course of pursuing academic activity in the areas of concentration, not necessarily related to sports, are financed in some countries, like the USA, probably not only for the sake of helping young people keep physically fit, but for their character formation as well. The idea of examining the role of a unique situation of the simultaneous pursuing of the academic and athletic activities as a real-life model of personality development occurred to the two authors of this project who had an opportunity to be a part of the National Collegiate Athletic Association while getting their Bachelor's degrees in psychology and political sciences in the USA (Wake Forest University from 2008 to 2012). The two activities under the conditions, described above, became interdependent and the participants of such programs had to share their attention and efforts equally between those activities to succeed in both and meet the program requirements.

As Eysenk, M. et al. (2007) claim, according to the Attention Control Theory, shifting attention between the simultaneously performed equally significant activities is likely to cause anxiety in the emotionally vulnerable individuals or make them activate their personality resources to succeed in attending to each of the two activities simultaneously. Being a student-athlete is both demanding and rewarding and leads to the acquisition of a number of character strengths, extends social contacts considerably and provides opportunities to experience a rare emotional state of the flow (Csikzentmihalyi \& Csikzentmihalyi, 2006) - the peak satisfaction with oneself at the moments of sporting triumph, equally as at the moments of academic success. This type of emotional experience qualitatively changes the personality attitude to oneself, others, the world at large. The specific situation, described above, in our opinion, belongs to the class of those situations, about which Baumeister (1999) argued as of the instances where the personality and social psychologists can and must collaborate in exploring person by situation interaction as the only defensible model of human behavior.

We think that the situation chosen in this research provides a realistic opportunity not only to stimulate personality development over youth but to make a young person become an agent of self-evolution. In this respect, we agree with J. Campbell's (2008) assessment of Kelly's analogy for understanding human behavior as that of the scientist (Kelly, 1955). His "man as a scientist" assumption stated that people behave in their lives as scientists do in their labs: they formulate hypotheses about what will happen if they act a certain way, and the outcome provides data that support or disconfirm the prediction. A good scientist, as Campbell reasoned, would revise hypotheses that were not supported, as would a healthy person do. A neurotic person, on the contrary, is like a bad scientist whose predictions are not validated but who is unwilling or unable to change them (Campbell, 2008).

Rotter (1954) also stated in his cognitive-social-learning theory of personality that a person would engage in a particular behavior in a particular situation when a given reinforce is available. He conceptualized that probability as a function of two factors: the person's expectancy that the behavior will lead to a particular reinforce, and the reinforcement value for that reinforce. In the situation chosen in our research project as a means of stimulating personality development there is a strong reinforce for both simultaneously pursued behaviors: academic and athletic activities and the reinforcement values of both activities are high. The situation is different, in our opinion, from that when the athletic activity is performed just for pleasure, recreation or for the sake of keeping fit. The person involved into the former type of a situation really begins to act as a scientist, performing a conscious reflective activity of appraising at each stage of the two interrelated activities their necessary outcomes, estimating the efforts required to achieve the rewarded goal and enhancing the self-regulative strategies.

Mischel, Shoda \& Mendoza-Denton (2002) described situation behavior profiles as a locus of consistency in personality that account for "if then" signatures of the personality. They claimed that cognitive-affective units include the person's representations of the self, people, and situations, goals, expectations-beliefs and feeling states. Mischel's CAPS model, along with the similar knowledge-and-appraisal personality architectture (Cervone, 2008) make possible to move toward integrative personality theories. The goals set by the key personality researchers are formulated as bringing specific findings back to the person.

The major objective of our exploratory study was to demonstrate that the qualitative changes that occurred in the personality dispositions of the academic athletes, involved into our research, accounted for their complex histories of winning the highest athletic titles despite injuries in the period of the successful reading toward their academic degrees.

\section{The Present Study}

To fully investigate the claimed qualitative changes that are likely to occur in the personality self-efficacy characteristics of the young people thanks to the simultaneous pursuing of the academic and athletic activities we involved into this research two natural groups of participants who have had a real-life experience of being exposed to the specific life situations of sharing attention between equally significant life tasks and had differences in sporting achievements.

The conceptual hypothesis of the research was formulated as follows: going in for sports in the course of acquiring education stimulates the personality self-efficacy dynamics that can be tapped by comparing the differences in personality characteristics of the participants with different levels of achievements in sports. We expected that the hypothesis will be proved if the higher level achievers statistically significantly differ in the majority of characteristics, indicative of the personality selfevolution. The main goals of this project were two-fold. The first goal was to identify personality variables indicative of the personality development stimulated by the simultaneous pursuing for a sufficiently long period of time of the academic and athletic activities. The second goal was to examine differences in the predictive expediency of various personality variables including a recently developed by a Ukrainian psychologist (as a part of her Ph.D. thesis) a new Inventory for assessing dispositional personality resources of becoming an agent of one's personality self-evolution (personality growth). 


\section{Method}

\section{Participants}

Two samples of research participants included: 30 university-level student-athletes, aged 18 to 24 (mean age 21.6), undergraduate and graduate students of different universities of Ukraine (Kiev, Dnipropetrovsk, Donetsk, \& others), members of the Ukrainian National team, as well as 109 student-athletes of the younger age (16 - 18 years, mean age 17.5), studying at Dnipropetrovsk secondary level College of Physical and Sports Culture. The participants of the first group were recruited to take part in the research during their training period at a sporting base where the national Ukrainian track and field team underwent training. In the first sample there were 16 males and 14 females. Among participants there were International Masters of Sports, Distinguished Masters of Sports, Masters of Sports and Candidates to the title of the Master of Sports, so they differed in their sporting experience and achievements, the lowest level of achievements being that of the Candidate to the title of the Master of Sports. The participants of the younger age group included equal numbers of males and females. Their college instructors provided to the authors of this research descriptions of their achievements in sports and studies. The second sample participants represented athletes with different levels of achievements: some of them were awarded by regional and nationallevel certificates of sporting achievements, while others had lower level of experience and achievements in sports.

\section{Materials}

Six groups of personality variables were assessed. The first group included coping strategies, measured by CISS (Endler and Parker, 1999 adapted to the Ukrainian culture in 2004 by Krukova). Reliability and validity estimates for the Ukrainian adaptation of CISS provide support for internal consistency of all the scales. Cronbach $\alpha=.876$ for the whole inventory; $\alpha$ $=.853$ for the problem-focused coping; $\alpha=.877$ for emotion focused coping and $\alpha=.814$ for the avoidance coping. The Inventory comprised 46 items, rated on a 7-point Likert scale ranging from 1 (strongly disagree) to 7 (strongly agree). By choosing this measure of personality we expected to examine the assumption that the individuals who have achieved a higher self-regulation level will demonstrate the preferred tendency to cope with stress by resorting to the problem-focused strategy rather than to emotion-focused and avoidance strategies. This will indicate that the more experienced and higher qualified athletes (Distinguished masters of sports and Master of sports) have developed in the course of frequent exposure to stressful situations, presenting failure threat, the ability to cope with stress.

We have also chosen the measure of Emotional Intelligence which is now conceptualized as a new dynamic trait. It was assessed with the help of the Emotional Intelligence Inventory (EmIn), designed by Russian researcher D.V. Lusin (2006). This inventory consists of 2 measures of the Intra-individual Emotional Intelligence (IEI) and Inter- individual (or Social) Emotional Intelligence (SEI).

IEI is represented, in its turn, by two variables: awareness of one's own emotions and control of emotions. The Social EI is represented by 3 variables: understanding emotions of other people, the ability to control other people's emotions, and regulation of one's own emotional expression.

Psychometric characteristics of all the scales and subscales of
EmIn are characterized by sufficiently high internal consistency: values of Cronbach $\alpha$ are within the range .79 to .69 . The choice of the Emotional Intelligence Inventory was determined by the considerations that in the course of sporting activities sportsmen are exposed very frequently to various types of emotional experience, both positive and negative, and observe other people's emotions which are usually expressed quite vividly and intensively. This stimulates the formation of the high level of EI.

Since we considered that combining sporting activities with the academic ones sets high demands to the abilities of the individuals to assume responsibility for the success and failure of the significant and highly rewarded activities, they would develop in the course of the simultaneous pursuing of the athletic and academic activities the internal locus of control. This will be a lawful consequential outcome of comprehending one's own responsibility for the success or failure of the significant activities, the success being a desirable and highly valued outcome. So, we chose the Rotter's Locus of Control Scale (1966), widely-used in adaptations for studying sporting activities. Cronbach $\alpha$ for the adaptation of Rotter's Locus of control Scale was .68. According to Rotter, locus of control is a unidimensional generalized measure of personal control and people with internal locus of control believe that by their own skills and efforts they can control their destiny. We chose three subscales scores to be included into the set of variables for cluster analysis: Internality in Appraising Success; Internality in Appraising Failure; and Internality in the main (professional) activity of the individual.

The above described measures represented the characteristic features of the psychological resources of our research participants, which are developed under the influence of the specific situation.

To assess the level of the authenticity the individuals acquired thanks to the simultaneous pursuing of the academic and athletic activities, we assessed changes in their consciousness that were claimed to reflect the personality self- evolution. As a measure of the growing authenticity we used the scores of the Maddi and Kobassa "Hardiness Inventory", (adapted by D. A. Leont'yev and E. I. Raskasova to the Russian sample in 2006). Reliability estimates found in the published studies, in which various versions of Kobassa's instrument have been used, provide support for internal consistency of both the total hardiness scores and those of the subscales within the range: $\alpha=.72$ to .77. It includes 3 subscale measures: commitment, control, challenge. S. Maddi defines authenticity as a qualitative personality characteristic feature. The authentic personality is characterized by the high level of social and personal reflection; inner discipline and autonomy; the ability to maintain favorable relations with other people. Authenticity is interpreted by the author as an integral moral property, which manifests itself in hardiness (Maddi, 2004; Maddi \& Koshaba, 2004).

To assess another important aspect of the change in consciousness manifested by the individual's awareness of oneself as an agent of self-evolution, we used a new Ukrainian thoughtout Inventory "Dispositional characteristics of the personality self-evolution" (Kusikova, 2012). The Inventory consists of 30 statements rated on a five-point Likert Scale (with 5 "very much like me" and 1 "not like me at all"). The statements are formulated like: "I believe in my potential abilities and strive to self-actualization"; "I enjoy doing things that require maximum commitment and efforts"; or "In my life I am guided by the 
ideals of the truthfulness, goodness and beauty" etc. The inventory has 3 scales. The meaning of the first scale "Need of self-evolution" is summed up by the author (Kusikova, 2012) as the awareness of the individual in the necessity of selfgrowth, reflected self-evolution; openness to changes, interest in the events of the surrounding world; interest in one's own inner world and that of other people; exuberance of life, need in expanding one's inner world.

The meaning of the second scale "Conditions of self-evolution" is defined in terms of: autonomy, positive self-perception, strength and maturity of the self-image; awareness of one's goals, active living strategies (activity in searching the new information, readiness for self-perception; tolerance of the ambiguity).

The meaning of the third scale: "Mechanisms (functional means) of self-evolution" is defined in terms of self-comprehension (strive to authenticity); self-reflection (self-analysis); awareness of the discrepancies between the real and the ideal self; sensitivity to the feed-back from other people, ability of self-regulation and self-determination. The author reports the acceptable internal consistency of the scales $\alpha>.70$.

We expected that if our hypothesis of the role of the simultaneous pursuing of the two significant activities in the character formation is valid, the participants with higher sporting and academic achievements will be characterized by the higher levels of their personality evolution, operationalized in terms of the qualitative characteristics in their personalities described above.

There was one more measure chosen-Mental Health Continuum. It was assessed by MHC-SF, designed by (Keyes, 2006). This short-form (14-item) scale provides measures of subjective well-being, psychological well-being and social wellbeing, claimed to be indicative of the mental health of the individuals. We do not describe this scale in more detail, as we used it in our own translation into the Ukrainian language without adaptation (as it is allowed by the author, if the scale is used for research). The short form has shown good internal consistency (Cronbach $\alpha=.80$ ) and discriminatory validity. Testretest reliability estimates range from .57 to .82 for the total scale (Keyes, 2007) The three-factor structure of the short form - emotional, psychological, and social well-being-has been confirmed in American representative samples (Keyes 2005, 2009).

All the variables were selected to characterize the participants' self-efficacy status achieved, their ability to motivate themselves to achievement, to overcome more successfully the bitterness of failures and motivate themselves to continue striving for success.

Internality in the Locus of control was also expected to be an important factor of the self-reliance acquisition in the course of pursuing two equally significant activities simultaneously.

The mental health continuum variables, including the subjective, psychological and social well-being components, are considered to be indicant of human stability, belief in one's selfefficacy. And, finally, the choice of the Hardiness variables, and those of the dispositional self-actualization tendencies were considered to be the most probable consequential outcomes of character development. Hardiness variables have been reported by other authors to be pertinent to the athletes in kinds of sports where competition is tough and personal courage is required to cope with obstacles.

Thus, all the personality variables chosen, in fact character- ized the dynamic integrated personality resources, necessary for coping with difficulties, regulating emotions and displaying courage.

\section{Procedure}

The participants of the first group filled in the suggested questionnaires individually and provided their demographic and sporting achievement details to the three authors of this project, who took part in the athletic activities together with them.

Since the research reported in this paper is in progress, the participants of the second group filled in only three questionnaires: Emotional Intelligence, Hardiness and Mental Health Continuum. Like the participants of the first group, they were also split into two opposite clusters on their personality variables in order to test the hypothesis of the research.

\section{Results}

As shown in Figure 1 and Table 1, we have identified using the method of cluster analysis two comparable clusters of participants in group 1, whose personality variables differ significantly on all the hypothesized self-efficacy characteristics.

There are evident inter-cluster differences between the means of all the coping strategies. The participants of $1^{\text {st }}$ cluster assumed to have a higher level of self-efficacy resources, appeared to display a specific pattern of coping strategies opposite to that of the $2^{\text {nd }}$ cluster participants: higher level of problem focused coping, lower level of emotion-focused and avoidance coping as well as the lower level of seeking social support. The participants of the $2^{\text {nd }}$ cluster display an almost symmetrical opposite pattern of the coping strategies combination.

As shown in Table 1, the differences between the means of all the coping strategies variables are significantly different at $p$ $<.001$ for the avoidance coping, $p<.015$ for the problem-focused coping and $p<.012$ for seeking social support strategy.

The statistically significant differences by t-test are Registered for all the variables reflecting different aspects of emotional intelligence (see Figure 1 and Table 1). As the test of emotional intelligence designed by Russian scholar D. Lyusin $(2006,2009)$ is a standardized one, it was possible to define that the participants of both clusters have high and very high leve1s of emotional intelligence. The integral mean values of emotional intelligence for both clusters are within the range of high values (integral level of EI for the cluster 1 is 109.21 and for cluster $2=96.18$ ). The EI data reveal inter-cluster differences in the majority of this variable, except control of one's own emotions and interpersonal EI.

Regarding the dispositional resources of self-evolution measures the hypothesized differences appeared valid for the "conditions" and "mechanisms" variables, while there were no differences for the "need" variable (see Table 2).

The locus of control appeared to be equally high in both clusters of participants and the differences in the absolute means did not reach the level of significance.

As to the results of the hardiness measures there appeared a pattern of inter-cluster differences similar to those of the dispositional resources of self-evolution measures. While there were no differences between the means of the second and first clusters on the "commitment" variable, the differences between the "control" and "challenge" variables were found out to be significant at $p<.009$ and $p<.049$, respectively. 


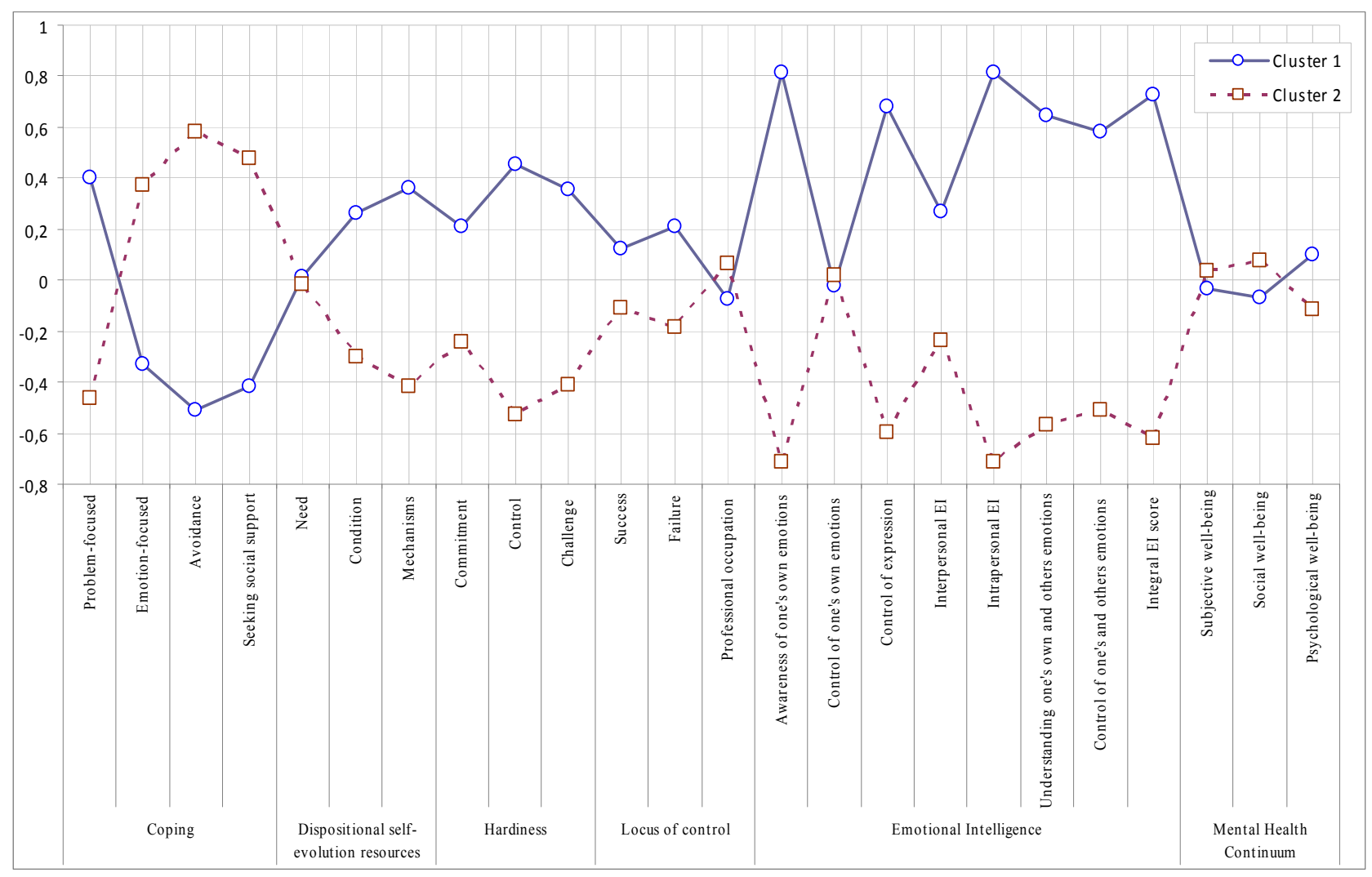

Figure 1.

The results of clusterization (k-means algorithm) of 30 university-level student-athletes on the personality variables.

Table 1.

Inter-cluster differences (K-means algorithm) in coping strategies and Emotional Intelligence scores of the group 1 participants $(\mathrm{N}=30)$.

\begin{tabular}{|c|c|c|c|c|c|}
\hline \multirow{2}{*}{ Variable } & \multicolumn{2}{|c|}{ Cluster 1} & \multicolumn{2}{|c|}{ Cluster 2} & \multirow{2}{*}{$\mathrm{t}$} \\
\hline & Mean & SD & Mean & SD & \\
\hline \multicolumn{6}{|l|}{ Coping } \\
\hline Problem-focused & 64.062 & 8.020 & 56.142 & 8.751 & $2.586^{*}$ \\
\hline Emotion-focused & 35.625 & 8.868 & 44.357 & 14.489 & -2.019 \\
\hline Avoidance & 42.063 & 10.195 & 53.143 & 6.188 & $-3.533^{* *}$ \\
\hline Seeking social support & 15.500 & 3.651 & 18.857 & 3.110 & $-2.690^{*}$ \\
\hline \multicolumn{6}{|l|}{ Emotional Intelligence } \\
\hline Awareness of one's own emotions & 23.786 & 2.887 & 27.688 & 2.301 & $6.434^{* *}$ \\
\hline Control of one's own emotions & 14.429 & 1.697 & 14.500 & 1.673 & -.116 \\
\hline Control of expression & 16.929 & 3.990 & 12.063 & 1.569 & $4.506^{* *}$ \\
\hline Interpersonal EI & 50.071 & 3.892 & 47.938 & 4.389 & 1.400 \\
\hline Intrapersonal EI & 59.143 & 5.333 & 48.250 & 3.890 & $6.448^{* *}$ \\
\hline Understanding one's own and others emotions & 51.643 & 5.017 & 45.125 & 3.612 & $4.121^{* *}$ \\
\hline Control of one's and others emotions & 57.571 & 5.653 & 51.063 & 4.464 & $3.521^{* *}$ \\
\hline Integral EI score & 109.214 & 7.827 & 96.188 & 6.431 & $5.004^{* *}$ \\
\hline
\end{tabular}

Note: ${ }^{*} p<.05,{ }^{* *} p<.001$. 
Table 2.

Inter-cluster differences (K-means algorithm) in the personality variables.

\begin{tabular}{|c|c|c|c|c|c|}
\hline \multirow{2}{*}{ Variable } & \multicolumn{2}{|c|}{ Cluster 1} & \multicolumn{2}{|c|}{ Cluster 2} & \multirow{2}{*}{$\mathrm{t}$} \\
\hline & Mean & SD & Mean & SD & \\
\hline \multicolumn{6}{|l|}{ Dispositional self-evolution resources } \\
\hline Need & 35.438 & 4.516 & 35.286 & 5.622 & .082 \\
\hline Condition & 40.438 & 5.501 & 37.786 & 3.239 & 1.578 \\
\hline Mechanisms & 35.000 & 4.705 & 31.786 & 2.607 & $2.267^{*}$ \\
\hline \multicolumn{6}{|l|}{ Locus of control } \\
\hline Success & 20.786 & 4.543 & 19.750 & 4.405 & .633 \\
\hline Failure & 20.643 & 4.254 & 19.063 & 3.820 & 1.072 \\
\hline Professional occupation & 16.571 & 3.155 & 17.125 & 4.617 & -.378 \\
\hline \multicolumn{6}{|l|}{ Hardiness } \\
\hline Commitment & 40.429 & 6.722 & 37.333 & 6.787 & 1.165 \\
\hline Control & 34.857 & 5.869 & 28.250 & 6.032 & $2.826^{* *}$ \\
\hline Challenge & 19.214 & 4.475 & 15.583 & 4.400 & $2.078^{*}$ \\
\hline \multicolumn{6}{|l|}{ Mental Health Continuum } \\
\hline Subjective well-being & 11.313 & 2.798 & 11.500 & 2.410 & -.195 \\
\hline Social well-being & 12.938 & 5.323 & 13.643 & 4.465 & -.390 \\
\hline Psychological well-being & 21.750 & 5.859 & 20.500 & 5.585 & .596 \\
\hline
\end{tabular}

Note: ${ }^{*} p<.05,{ }^{* *} p<.01$.

No differences were found between the measures of the mental health continuum, the participants of both clusters having high levels of emotional, social and psychological well-being and above medium levels of social and subjective well-being.

Tables 3 and 4 report the descriptive statistics of the demographic data in group 1 (university-level students). Inspection of the tables indicates that the two clusters, into which the participants were split by the cluster analysis, appeared to be segregated on the gender and sporting qualification variables. In cluster 1 there are $75 \%$ of males, in cluster 2-respectively$28.6 \%$ (see Table 3).

The clusters also differ in the number of participants having different sporting titles-cluster 1 includes $93.8 \%$ of the Distinguished Masters of Sports and Masters of Sports (see Table 4), while cluster 2 includes $57.1 \%$ of the athletes of higher sporting qualification.

The results of EI measures in group 2 (younger student-athletes) show that participants of cluster 1 display high level of emotional intelligence: their data lie within the standardized values of the high-level range (98 - 104). The participants of cluster 2 have the integral value of EI on the borderline between the medium and low ranges of the standardized tests. All the inter-cluster differences of EI measures are statistically significant.

In group 2 the Hardiness measures in clusters 1 and 2 are statistically significant (see Table 5). The same regularity is observed for the MHC results.

In the sample of the group 2 participants the similar picture is observed. Cluster 2 with the lower level of the self-efficacy resources (lower EI and Hardiness scores) is made up of the student-athletes who have not yet distinguished themselves in sports. Cluster 1 which has statistically higher EI and Hardiness scores includes $80 \%$ of the participants who have higher sport- ing achievements. MHC inter-cluster differences are also statistically significant in this group of participants (see Table 5).

\section{Discussion and Conclusion}

In the present study an attempt was made to theoretically substantiate and empirically test the hypothesis that personality differences manifest themselves most vividly through the interplay of the specific life situations and the new contextualized trait constructs that are formed at the borderlines of abilities and personality, cognition and personality, values and personality etc.

On two samples of participants - 30 university-level studentathletes and 109 secondary-college student athletes, it was demonstrated that the individuals who possess higher levels of personality resources to cope with stressful situations, emotional intelligence, hardiness manage to successfully cope with shifting attention between two equally-significant life-tasks: simultaneously pursuing sporting and academic activities.

Though the scope of the exploratory empirical research was limited, the sample of thirty university-level student-athletes appeared to be clustered (K-means algorithm) on their personality variables, indicative of the level of personality self-evolution attained, into comparable groups of sixteen and fourteen participants. The results showed that the participants of the $1^{\text {st }}$ cluster comprised of the athletes with higher sporting titles statistically differed on the coping strategies patterns. It allows to claim that coping strategies can be viewed as an integral conceptualized dynamic personality trait referred to, using Parker's and Wood's terminology, as "specific adaptations".

Our empirical data also seem to support the possibility of ascribing to emotional intelligence the status of a new contextualized integral dynamic trait. The fact that all the participants of 
Table 3.

Inter-cluster gender differences.

\begin{tabular}{ccccccc}
\hline \multirow{2}{*}{ Participants clustered (K-means algorithm) on the personality variables } & \multicolumn{2}{c}{ Males } & \multicolumn{2}{c}{ Females } & \multirow{2}{*}{ Total number participants } \\
\cline { 2 - 5 } & $\mathrm{N}$ & $\%$ & $\mathrm{~N}$ & $\%$ & 16 \\
\hline Cluster 1 & 12 & $75 \%$ & 4 & $25 \%$ & 14 \\
Cluster 2 & 4 & $28.6 \%$ & 10 & $61.4 \%$ & \\
\hline
\end{tabular}

Note: $\varphi_{\mathrm{e}}^{*}=2.641$, sig. $p<.0067$.

Table 4.

Inter-cluster differences in the percentage of participants with the highest (Distinguished Masters and Masters of sports) and the lowest (Candidates to the Masters of sports) sporting titles.

\begin{tabular}{|c|c|c|c|c|c|}
\hline \multirow{2}{*}{$\begin{array}{c}\text { Participants clustered } \\
\text { (K-means algorithm) } \\
\text { on the personality variables }\end{array}$} & \multicolumn{2}{|c|}{$\begin{array}{c}\text { Participants with the highest titles } \\
\text { (Distinguished Masters and Masters of Sports) }\end{array}$} & \multicolumn{2}{|c|}{$\begin{array}{l}\text { Participants with the lower titles } \\
\text { (Candidates to the Masters of Sports) }\end{array}$} & \multirow{2}{*}{$\begin{array}{l}\text { Total number of } \\
\text { participants }\end{array}$} \\
\hline & $\mathrm{N}$ & $\%$ & $\mathrm{~N}$ & $\%$ & \\
\hline Cluster 1 & 15 & $93.8 \%$ & 1 & $6.2 \%$ & 16 \\
\hline Cluster 2 & 8 & $57.1 \%$ & 6 & $42.9 \%$ & 14 \\
\hline
\end{tabular}

Note: $\varphi_{\text {emp }}^{*}=2.520$, sig. $p<.01$.

Table 5.

Inter-cluster differences (K-means algorithm) in the personality variables of 109 secondary level students of College of Phisical Education.

\begin{tabular}{|c|c|c|c|c|c|}
\hline \multirow{2}{*}{ Variable } & \multicolumn{2}{|c|}{ Cluster 1} & \multicolumn{2}{|c|}{ Cluster 2} & \multirow{2}{*}{$\mathrm{t}$} \\
\hline & Mean & SD & Mean & SD & \\
\hline \multicolumn{6}{|l|}{ Emotional Intelligence } \\
\hline Awareness of one's own emotions & 21,021 & 3,685 & 15,887 & 2.463 & $8.704^{*}$ \\
\hline Control of one's own emotions & 17,148 & 2,718 & 12,935 & 3.258 & $7.170^{*}$ \\
\hline Control of expression & 12,744 & 3,280 & 10,419 & 3.419 & $3.578^{*}$ \\
\hline Interpersonal EI & 46,744 & 6,693 & 38,596 & 5.460 & $6.996^{*}$ \\
\hline Intrapersonal EI & 50,914 & 6,810 & 39,241 & 6.585 & $9.031^{*}$ \\
\hline Understanding one's own and others emotions & 46,404 & 6,138 & 36,258 & 4.998 & $9.508^{*}$ \\
\hline Control of one's and others emotions & 51,255 & 6,019 & 41,580 & 6.318 & $8.079^{*}$ \\
\hline Integral EI score & 97,659 & 10,428 & 77,838 & 8.604 & $10.866^{*}$ \\
\hline \multicolumn{6}{|l|}{ Hardiness } \\
\hline Commitment & 37.001 & 2.404 & 34.048 & 2.138 & $6.763^{*}$ \\
\hline Control & 35.002 & 2.386 & 32.080 & 2.137 & $6.715^{*}$ \\
\hline Challenge & 15.553 & 1.599 & 13.548 & 1.752 & $6.140^{*}$ \\
\hline \multicolumn{6}{|l|}{ Mental Health Continuum } \\
\hline Subjective well-being & 10.085 & 1.529 & 8.338 & 1.085 & $6.970^{*}$ \\
\hline Social well-being & 19.978 & 1.594 & 18.016 & 1.674 & $6.185^{*}$ \\
\hline Psychological well-being & 23.744 & 1.607 & 22.693 & 1.421 & $3.613^{*}$ \\
\hline
\end{tabular}

Note: ${ }^{*} p<.001$.

our study (in both groups of 30 and 109 student-athletes) demonstrate the same regularity, namely: the higher is the level of achievements in sports, the higher is the level of emotional intelligence attained, speaks in favor of the personality-evolution potential of the simultaneous pursuing of academic and athletic activities. The explanation of the role of sporting activities in the development of EI is prompted by the Laws of Emotions (Frijda, 2006). The thing is there exists "the Law of Momentum" according to which the intense emotions make a deep impact on the personality growth. The significant events in life (like failures in achieving worthy goals and moments of triumph in winning recognition when the person distinguishes oneself), stimulate the personality evolution. Our empirical results supports the hypothesis that the specific life situation of simultaneously pursuing two equally significant activities does stimulate personality evolution and results in the acquisition of the new dynamic personality traits (like those of "specific adaptations" and "Emotional intelligence").

Our empirical data also suggest that this life situations find reflection in the consciousness of the individuals. 
The fact that the participants, belonging to cluster 1 (with higher level of the personality self-efficacy resources) who in sample 1 (university-level students) do not differ from the participants of cluster 2 in "commitment" (measured by Hardiness Inventory), but do differ on the scales of "control" and "challenge", speaks in favor of our claim that this type of life experience stimulates the personality evolution.

Equally high levels of the Mental Health Continuum of our research participants in sample 1 and higher levels in cluster 1 of sample 2 (younger sportsmen with high levels of sporting achievements) can be interpreted as a favorable consequential outcome of combining athletic and academic activities over youth for the personality self-evolution.

Further prospects of this promising research presuppose extending the sample and continue testing the major hypothesis on the samples of sportsmen and non-sportsmen, as well as on the sportsmen going in for the so called collective types of sports. Our research participants represented an individual type of sporting activities. We have observed higher levels of intraindividual emotional intelligence pertinent to them as compared to the social intelligence. The very fact is an argument in favor of the hypothesis of this study and may be made an aspect of a special study on the role of different kinds of sports.

\section{Acknowledgements}

The authors thank Professor Eleonora Nosenko of Dnipropetrovsk National University for help in structuring the material of this research and for language editing of the manuscript. Financial disclosures: the authors have no conflict of interest to declare.

\section{REFERENCES}

Arshava, I. F. (2008). A reflected behavioral manifestation of the human emotional stability. Abstracts of the 29th International Congress of Psychology. Berlin, 20-25 July 2008. International Journal of Psychology, 43, 622-623.

Arshava, I. F., Ponomareva, L. F., \& Nosenko, E. L. (2010). Crosssituation consistency of the behavior self-regulation of an evidence of the trait-like nature of coping strategies. 15th European Conference on Personality, Brno, 20-24 July 2010, 225.

Austin, E. J., Saklofske, D. H., \& Egan, V. ( 2005 ). Personality, wellbeing and health correlates of trait emotional intelligence . Personality and Individual Differences, 38, 547-558.

doi:10.1016/j.paid.2004.05.009

Baumeister, R. F. (1999). The nature and structure of the self: An overview. In R. Baumeister (Ed.), The self in social psychology (pp. 1-20). Philadelphia, PA: Psychology Press (Taylor \& Francis).

Boyle, G., Matthews G., \& Saklofske D. (2008). Handbook of personality theory and assessment. Vol. 1. Personality theories and models. Los Angeles, CA: Sage Publishers.

Campbell, J. B. (2008). Modern personality theories: What have we gained, what have we lost? In G. Boyle, G. Matthews, \& D. Saklofske, SAGE Handbook of personality theory and assessment. Vol. 1. Personality theories and models (pp. 190-212). Los Angeles, CA: Sage Publishers.

Cervone, D. (2008) Explanatory models of personality: Social-cognitive theories and the knowledge and appraisal model of personality architecture. In G. J. Boyle, G. Matthews, \& D. Saklofske (Eds.), The SAGE handbook of personality and assessment. Vol. 1. Personality theories and models (pp. 80-101). Los Angeles, CA: SAGE Publication Ltd.

Cervone, D., Shadel, W. G., Smith, R. E., \& Fiori, M. (2006). Selfregulation: Reminders and suggestions from personality science. Applied Psychology: An International Review, 55, 333-385. doi:10.1111/j.1464-0597.2006.00261.x

Chebykin, A. Y., \& Abolin, L. M. (1984). Investigation of emotional stability and psychological approaches to its development in sportsmen. Psychological Journal, 4, 83-89.

Csikszentmihalyi, M., \& Csikszentmihalyi, I. S. (2006). A life worth living: Contributions to positive psychology (pp. 3-14). Oxford, NY: Oxford University Press.

Endler, N. S., \& Parker, J. D. A. (1999). Coping inventory for stressful situations (CISS): Manual (2nd ed.). Toronto: Multi-Health Systems.

Eysenck, M. W., Derakshan, N., Santos, R., \& Calvo, M. G. (2007). Anxiety and cognitive performance: Attention control theory. Emotion, 7, 336-353. doi:10.1037/1528-3542.7.2.336

Frijda, N. H. (2006). The laws of emotion. Mahwah, NJ: Lawrence Erlbaum Associates Publishers.

Golby, J., \& Sheard, M. (2004). Mental toughness and hardiness at different levels of rugby league. Personality and Individual Differences, 37, 933-942. doi:10.1016/j.paid.2003.10.015

Kelly, G. A. (1955). The psychology of personal constructs. New York: Norton.

Keyes, C. L. M. (2006). Mental health in adolescence: Is America's youth flourishing? American Journal of Orthopsychiatry, 76, 395402. doi:10.1037/0002-9432.76.3.395

Keyes, C. L. M. (2007). Promoting and protecting mental health as flourishing: A complementary strategy for improving national mental health. American Psychologist, 62, 95-108. doi:10.1037/0003-066X.62.2.95

Krukova, T. L. (2000) On assessing coping behavior of the contemporary youth. In P. Tula (Ed.), Psychology on the borderline of ages, 48-51.

Kusikova, S. (2012). Psychological fundamentals of the development of the personality self-evolution over youth. Sumy: "MacDen" Publishing.

Lyusin, D. (2006) Emotional intelligence as a mixed construct: Its relation to personality and gender. Journal of Russian and East European Psychology, 44, 54-68. doi:10.2753/RPO1061-0405440604

Lyusin, D. (2009). Emotional intelligence inventory (EmIn): New psychometric data. In D. V. Lyusin, \& D. V. Ushakov (Eds), Social and emotional intelligence: From models to assessment (264-278). Moscow: Institute of Psychology Publishing.

Maddi, S., \& Khoshaba D. (2004). HardiTraining. Managing Stress for performance and health enhancement. Irvine: The Hardiness Institute.

Maddi, S. (2004). Hardiness: An operationalization of existential courage. Journal of Humanistic Psychology, 44, 279-298. doi: $10.1177 / 0022167804266101$

Maddi, S. R. (1999). The personality construct of hardiness: Effects on experiencing coping and strain. Consulting Psychology Journal: Practice and Research, 51, 2, 83-94. doi:10.1037/1061-4087.51.2.83

Maddi, S. R., \& Hess, M. J. (1992). Personality hardiness and success in basketball. International Journal of Sport Psychology, 23, 360368.

Mikolajczak, M., Luminet, O., \& Menil, C. (2006). Predicting mental and somatic resistance to stress: the incremental validity of trait emotional intelligence over alexithymia and optimism. Psicothema, 18, 79-88.

Mischel, W., Shoda, Y., \& Mendoza-Denton, R. (2002). Situationbehavior profiles as a locus of consistency in personality. Current Directions in Psychological Science, 11, 50-54. doi:10.1111/1467-8721.00166

Nosenko, E. L., \& Arshava, I. F. (2009). Health enhancing function of problem-focused coping strategy. Psychology \& Health, 24, 2009, 85.

Nosenko, E. L., \& Kovriga, N. V. (2001). Trait-oriented approach to operationalizing emotional Intelligence. Abstracts of the 7th European Congress of Psychology, London, 1-6 July 2001, 211.

Nosenko, E., Arshava, I., Nosenko, D., \& Nosenko, A. (2012). The role of the simultaneous pursuing of athletic and academic activities in mental health enhancement. Abstract of 26th Conference of the European Health Psychology Society, Prague, 21-25 August 2012. doi:10.1080/08870446.2012.707817

Parker, J. D. A., Summerfeldt, L. J., Hogan, M. J., \& Majeski, S. A. 


\section{ARSHAVA ET AL.}

(2004). Emotional intelligence and academic success: Examining the transition from high school to university. Personality and Individual Differences, 36, 163-172. doi:10.1016/S0191-8869(03)00076-X

Peterson, C., \& Seligman, M. E. P. (2004). Character strengths and virtues: A handbook and classification. New York: Oxford University Press.
Rotter, J. B. (1954). Social learning and clinical psychology. Englewood Cliffs, NY: Prentice-Hall. doi:10.1037/10788-000

Sheard, M., \& Golby, J. (2007). Hardiness and undergraduate academic study: The moderating role of commitment. Personality and Individual Differences, 43, 579-588. doi:10.1016/j.paid.2007.01.006 